\title{
Política pública inovadora de geração de renda e desenvolvimento local: 0 caso da Câmara de Animação Econômica da Subprefeitura do Itaim Paulista (CAE-IT), São Paulo, Brasil
}

\author{
Carmen Augusta Varela \\ Centro Universitário da FEI-São Paulo e Fundação Getulio Vargas de São Paulo \\ César Yojiro Matsumoto \\ Escola de Diálogo de São Paulo
}

\begin{abstract}
O objetivo deste artigo é avaliar, por meio de um estudo de caso único, o funcionamento da Câmara de Animação Econômica da Subprefeitura do Itaim Paulista (CAE-IT), mecanismo pelo qual se buscou fomentar trabalho e geração de renda. A região tem cerca de 380 mil habitantes, um alto índice de violência e um grande número de jovens sem acesso à educação básica e sem oferta de emprego. Diante disso, em 2005, a Subprefeitura articulou-se com uma série de parceiros com quem desenvolveu a ideia da CAE-IT. Inicialmente, buscou compreender a realidade local, através da análise de dados secundários. Em seguida, houve consulta a agentes comunitárias de saúde para compreender quais eram as vocações econômicas da região e em qual público-alvo a política deveria focar esforços. A decisão final foi dar ênfase à promoção de arranjos produtivos locais envolvidos com reciclagem de lixo.
\end{abstract}

Palavras-chave: política pública; inovação; geração de emprego e renda; desenvolvimento local.

Política pública innovadora del generación de rienda y desarrollo local: el caso de la Câmara de Animação Econômica de la Subprefectura de Itaim Paulista (CAE-IT), São Paulo, Brasil

El objetivo de este trabajo es evaluar, por medio de un estudio de caso único, el funcionamiento de la Câmara de Animação Econômica da Subprefeitura do Itaim Paulista (CAE-IT), mecanismo por el cual se buscó promover el trabajo y la generación de rienda. La región cuenta con cerca de 380.000 habitantes, una alta tasa de violencia y un gran número de jóvenes sin acceso a educación básica y a oferta

\footnotetext{
"Artigo recebido em 19 ago. 2011 e aceito em 28 maio 2012. Este trabalho foi apresentado no XIV Congreso LatinoIberoamericano de Gestión Tecnológica: innovación para el crescimiento sostenible en el marco del Bicentenario — Altec 2011, realizado em Lima, no Peru, de 19 a 21 de outubro de 2011. Os autores agradecem ao editor e aos pareceristas anônimos pelos comentários e sugestões, isentando-os de eventuais erros e omissões. Agradecem também a todos os membros da Câmara de Animação Econômica da Subprefeitura do Itaim Paulista (CAE-IT) e da Secretaria de Desenvolvimento Econômico e do Trabalho da Prefeitura Municipal de São Paulo.
} 
de trabajo. Así, en 2005, la Subprefeitura se articuló con una serie de socios con los cuales desarrolló la idea de la CAE-IT. Inicialmente, tratando de comprender la realidad local, a través del análisis de datos secundários. Luego fueron consultados agentes del servicio de salud para entender cuáles eran las vocaciones económicas de la región y los destinatários en que la política debe centrar sus esfuerzos. La decisión final fue la promoción de arreglos productivos locales que participan en el reciclaje.

Palabras clave: política pública; la innovación; el empleo y la generación de rienda; el desarrollo local.

Innovative public policy of income generation and local development: the case of the Câmara de Animação Econômica of the Itaim Paulista Subprefecture (CAE-IT), São Paulo, Brazil

The aim of this paper is to evaluate, through a single case study, the functioning of the Câmara de Animação Econômica da Subprefeitura do Itaim Paulista (CAE-IT), a mechanism by which it sought to promote work and income generation. The region has about 380,000 inhabitants, a high rate of violence and a large number of young people without access to basic education and no job offer. Thus, in 2005, the Subprefeitura do Itaim Paulista articulated with a series of partners developed the idea of CAE-IT. Initially, they sought to understand the local reality, through the analysis of secondary data. Then, there was a consultation with community health workers to understand what were the economic vocations of the region and in which public policy should focus on targeted efforts. The final decision was to focus on promotion of local productive arrangements involved in waste recycling.

KEY words: public policy; innovation; employment and income generation; local development.

\section{Introdução}

O presente trabalho consiste em uma avaliação de uma política pública de desenvolvimento econômico local concebida na subprefeitura do Itaim Paulista. Formada pelos distritos de Itaim Paulista e Vila Curuçá, totalizando $21,7 \mathrm{~km}^{2}$, essa subprefeitura tem aproximadamente 380 mil habitantes e é marcada pela exclusão social. Esses distritos ocupam, respectivamente, o segundo e o sétimo lugares no ranking do índice de exclusão dos 96 distritos do município. Uma crescente população jovem não teve e continua sem acesso a educação básica, atividades culturais e emprego. O perfil da região é de "bairro dormitório", em que a maioria da população apenas reside no local, indo trabalhar nas áreas centrais da cidade.

No ano de 2005, o subprefeito da região desenvolveu e implementou a Câmara de Animação Econômica do Itaim Paulista (CAE-IT). Definiu-se que o foco do projeto seriam os "empreendedores latentes e emergentes", aqueles que ganhavam de zero a três salários mínimos, que não eram dependentes da assistência social, ou que não precisariam de uma política voltada a combater a exclusão social. Os segmentos econômicos definidos como alvo da CAE-IT foram divididos nas seguintes Câmaras Temáticas (CTs) para focar esforços de assessoramento: CT Moda e Artesanato; CT Reciclagem; CT Alimentação; CT Cultura e Informação, e CT Pequenos Negócios. Para a implementação e o desenvolvimento da política houve articulação e cooperação de inúmeros parceiros, entre eles, universidades, órgãos multilaterais, empresas, outras instâncias do governo municipal e estadual, consultores autônomos e voluntários. 
A pesquisa buscou compreender o funcionamento da Câmara de Animação Econômica sob a luz das teorias acerca do desenvolvimento local. Essa análise da realidade contraposta ao marco teórico permitiu uma avaliação da política pública, propondo sugestões de melhoria, bem como aspectos a serem levados em conta no caso de se replicar a metodologia da CAE-IT.

A primeira parte deste trabalho discorre sobre o referencial teórico adotado para a compreensão do desenvolvimento local: as concepções, as abordagens, o processo do planejamento do desenvolvimento local e a replicação de boas práticas. Em seguida, trata da compreensão da CAE-IT, que se inicia pela contextualização do território, onde são apresentados dados demográficos, econômicos e sociais sobre a região do Itaim Paulista e Vila Curuçá.

Uma vez contextualizados a região e o desafio em que se insere a subprefeitura do Itaim Paulista, a parte seguinte apresentará o processo de formação da CAE, narrando os encaminhamentos tomados ao longo do percurso pelos agentes envolvidos. Na sequência, o trabalho discorre sobre o diagnóstico e avaliação da política pública CAE, do ponto de vista de seus aspectos positivos e a melhorar.

\section{Referencial teórico}

De acordo com Martinelli e Joyal (2004), o conceito de desenvolvimento local diz respeito ao aperfeiçoamento em relação a um conjunto de valores, ou a uma atitude comparativa com respeito a esse conjunto, sendo esses valores condições e/ou situações desejáveis para a sociedade, em âmbito socioterritorial, quando esse processo é pensado, planejado, promovido ou induzido. A expressão desenvolvimento local é, normalmente, utilizada por diversos atores e abrange multidimensionalidade de fatores que apresentam certa relação de complementaridade (Sausen, Patias e Allebrandt, 2011). São eles fatores econômicos, ambientais, sociais, éticos, políticos, tecnológicos, legais, educacionais e culturais. Liga-se, sobretudo, à melhoria da qualidade de vida dos participantes de uma comunidade, seja na ampliação da renda, do poder de consumo, seja na expansão das liberdades individuais (Martinelli e Joyal, 2004; Speranza, 2006).

Autores como Silva, Tondo e Lima (2007) reforçam a ideia de que para haver desenvolvimento é necessário ter geração de renda e, para que isso seja possível, deve haver geração de empregos que ofereçam condições apropriadas para que eles possam ser exercidos. Blakely e Bradshaw (2002) enfocam as relações do local junto à sua potencialidade de desenvolvimento. Já Martins, Vaz e Caldas (2010) lembram que o debate em torno do conceito e da prática do desenvolvimento local sofre uma crítica substantiva e falta de consenso, tanto no Brasil como no exterior.

A justificativa para o foco no território e a importância do local é expressa por Camarotti (2004). Segundo essa autora, o "local", sendo entendido como espaço do dia a dia, permite reinventar novas formas de políticas públicas e sua respectiva gestão, possibilitando a transgressão de pensamentos e modelos únicos e globalizados e o surgimento de inovações 
sociais. A partir da noção de local, imbuído nos participantes de uma comunidade, o conceito de desenvolvimento local se liga ao processo que reforça as comunidades e propicia o estreitamento de laços e vínculos comunitários. Partindo desse escopo, emerge a noção de capital social, como conceito que integra a ação coletiva, a participação cidadã, a convivencialidade e a cultura cívica numa territorialidade. De Paula (2001) considera capital social o estabelecimento de um conjunto de valores ou normas informais, que sejam aceitos pelos membros de um grupo ou comunidade e que favoreçam a cooperação entre esses membros.

De acordo com Abramovay (2000), o destaque que se dá ao termo capital social é resultado da derrocada do mito de que a sociedade é alicerçada por indivíduos independentes, agindo de acordo com os próprios interesses. Assim, o desenvolvimento necessita de condições institucionais para ocorrer de maneira fértil. Diante desse contexto, o conceito de desenvolvimento local perpassa por uma análise e fortalecimento institucionalista da territorialidade, visando à emergência de atividades resultantes da vida socioeconômica de um grupo que se apresenta "socialmente coeso".

$\mathrm{Na}$ esfera do local, diversos são os integrantes responsáveis pelo processo do desenvolvimento. Parcerias entre governos locais e organizações não estatais, entendidas como todas aquelas que não fazem parte da administração pública direta ou indireta, se mostram como potencialidades latentes, uma vez que cada um aporta recursos (financeiros, humanos e materiais) de acordo com suas aptidões, num espaço de construção coletiva de sinergias e cooperação, para que se consiga atingir um objetivo comum (Spink, 2001; Vasconcellos e Vasconcellos, 2009). Martins e Caldas (2009) apontam que um dos benefícios possíveis de serem obtidos com as parcerias é a criação de um espaço de interação entre os indivíduos envolvidos no processo, onde eles tenham condições de exercer a cidadania.

Spink $^{1}$ (2001) demonstra a importância que as alianças não estatais têm na promoção de políticas públicas inovadoras, bem como em sua continuidade. Em suas palavras: "Não é por acaso que nos $88 \%$ de programas e projetos que sobreviveram às trocas de governo municipal de 1996 para 1997, quase todos tiveram diferentes formas de parceria" (Spink, 2001:147).

Nos últimos anos, as teorias sobre desenvolvimento regional têm sofrido transformações diversas. Todavia, a questão regional passa a ser o maior foco das atenções a partir da teoria do desenvolvimento endógeno (Amaral Filho, 2001; Clemente e Higachi, 2000). O avanço proporcionado pela teoria endógena consiste na importância que se passa a dar aos agentes locais, na forma de capital social, capital humano, instituições, conhecimento tecnológico e cultural. Tendo o foco na geração de externalidades positivas que advenham da proximidade, cooperação e organização entre atores locais, sobretudo as micro e pequenas empresas, passa-se a pensar sobre as "economias de aglomeração", refletidas a partir dos conceitos de

\footnotetext{
${ }^{1} \mathrm{O}$ autor parte da base de dados do Programa Gestão Pública e Cidadania da FGV em parceria com o BNDES e Fundação Ford. Conta com mais de 400 experiências exitosas de gestão pública, abrangendo temas diversos, entre eles saúde, educação, geração de renda etc., em cinco anos de duração do Programa (1996 a 2000).
} 
"distritos industriais" - as concentrações de micro e pequenas empresas localizadas ao redor de grandes indústrias (Marshall, 1996) — e, mais recentemente, de clusters (Porter, 1990; Amaral Filho, 2001).

A aglomeração entre agentes para o desenvolvimento endógeno está associada ao conceito de competitividade (Cassiolato e Szapiro, 2003), ou como vantagem competitiva (Porter, 1990). A cooperação entre atores, atrelada também a processos de aprendizagem e inovação num território, é o que caracteriza a noção de arranjo produtivo local (APL).

De acordo com Cassiolato e Lastres (2003), arranjos produtivos locais são aglomerações territoriais entre agentes econômicos, políticos e sociais, que têm foco em um conjunto específico de atividades econômicas e que apresentam vínculos entre si. Portanto, além das empresas, governo, organizações de fomento e financiamento, de ensino e pesquisa, agências de cooperação, organizações não estatais concentram esforços no território para promover sinergias que visem o desenvolvimento local. Partindo de uma base setorial, os APLs aproveitam uma oportunidade existente e se especializam naquela base produtiva.

Meyer-Stamer (2004) reforça a distinção entre Desenvolvimento Econômico Local (DEL) e Desenvolvimento Social. Este último estaria mais relacionado a políticas compensatórias e ao apoio ao setor informal. Possui um viés de política social, como saúde, educação, moradia, entre outros. Já o DEL diz respeito à promoção de pequenas e médias empresas (PMEs), investimento no mercado de trabalho e empreendedorismo. Possui um viés ligado a negócios e competitividade. Os dois não são conceitos estanques. O envolvimento comunitário se mostra necessário para o desenvolvimento econômico e ambos são importantes para o desenvolvimento local. O problema maior dessa confusão entre os dois termos está nos resultados, em que nem os objetivos econômicos, nem os sociais são atingidos. Já Silveira, Bocayuva e Zapata (2001:245) entendem o desenvolvimento local como "importante inflexão na trajetória dos experimentos voltados para a reversão das dinâmicas geradoras de exclusão social, que marcaram a década de 90". Para os autores, o desenvolvimento local permeia fundamentalmente o social, enquanto combate à exclusão.

Blakely e Bradshaw (2002) conceberam uma metodologia de planejamento do desenvolvimento econômico local (DEL), que enfoca a geração de trabalho e renda para determinada comunidade. Em sua abordagem, partem da premissa de que o setor público é responsável por intervir na economia, guiando investimentos privados para gerar resultados desejados, favorecendo camadas de baixa renda e minorias étnicas. Os referidos autores propõem seis fases do processo de planejar o DEL, que podem ser traduzidas em três etapas básicas, na seguinte ordem: educação própria, desenvolvimento de uma estratégia e implementação de projetos. Camarotti e Spink (2003) salientam que os projetos e as experiências de desenvolvimento local não começam totalmente estruturados. Teriam mais características de processos que de atividades planejadas antecipadamente. "Estratégias, portanto, são muito mais um reconhecimento posterior de encaminhamentos adaptados, do que etapas programáticas anteriormente definidas" (Camarotti e Spink, 2003:193).

Tendo em vista a cautela com a "disseminação de melhores práticas", Silveira, Bocayuva e Zapata (2001) destacam elementos transformadores a partir da análise de diversos 
experimentos, e que se mostram como possibilidades, mais do que adaptação de modelos prontos. Esse conjunto de elementos representa caminhos já percorridos, assim como aponta possibilidades de percurso para o desenvolvimento local.

O modelo proposto por Blakely e Bradshaw (2002) apresenta um processo estruturado de se pensar o planejamento local. Entretanto, conforme apontam Meyer-Stamer (2004) e Camarotti e Spink (2003), o planejamento e a estratégia seriam muito mais processos identificados a posteriori, que diriam respeito ao processo de adaptar e encaminhar ações ao longo do tempo, sem necessariamente prevê-las de antemão. Essa constatação deve estar presente em uma avaliação de política pública, na medida em que faz jus ao processo de contínua adaptação e aprendizagem, mas que ao mesmo tempo leve em conta os elementos destacados por Silveira, Bocayuva e Zapata (2001).

\section{Metodologia}

O objetivo geral deste artigo é observar, mediante a análise de um estudo de caso único, a forma de funcionamento da Câmara de Animação Econômica criada e implementada pela subprefeitura do Itaim Paulista. Para atingir este objetivo geral foram considerados os seguintes objetivos específicos: 1) levantar na bibliografia o estado da arte da discussão sobre desenvolvimento local; 2) entender o funcionamento da CAE-IT; e 3) levantar dados para poder fazer, ainda que de forma exploratória, uma avaliação dos resultados da política.

De acordo com Yin (2001:19), é possível a utilização do método de estudo de caso, quando o foco do trabalho "se concentra em fenômenos contemporâneos inseridos em algum contexto da vida real". A escolha do estudo de caso único se justifica pelo fato de não ser muito comum encontrar a elaboração e a implementação de políticas públicas de desenvolvimento local no âmbito de subprefeituras.

As evidências para um estudo de caso podem ser originárias de seis fontes diferentes: 1) documentos; 2) registros em arquivo; 3) entrevistas; 4) observação direta; 5) observação participante; e 6) artefatos físicos (Yin, 2001). Para este estudo, os autores consideraram mais adequada a utilização dos quatro primeiros tipos de fontes.

Para atingir o primeiro e parte do terceiro objetivos específicos do trabalho foi utilizada a pesquisa bibliográfica e documental e a análise de dados secundários. Com a finalidade de atingir o segundo objetivo específico da pesquisa e parte do terceiro foram realizadas entrevistas e observações diretas.

Tentando entender o funcionamento da política de desenvolvimento local, foi feita uma pesquisa exploratória, onde se buscou analisar livros e artigos que tratavam sobre o tema, para embasar o marco teórico adotado na pesquisa. Em seguida, foram levantados e analisados dados secundários sobre a região em estudo e foram analisados relatórios sobre a implantação da referida política pública, divulgados por instituições de pesquisa ou pela própria subprefeitura do Itaim Paulista, em documentos escritos ou divulgados em websites. 
Na sequência, foram realizadas entrevistas em profundidade com servidores públicos e outros agentes envolvidos com a implementação da política.

Para as entrevistas foi elaborado um questionário semiestruturado e, em setembro de 2010, ocasião em que foi realizada uma visita ao CAE-IT, foi feita uma entrevista em profundidade com a coordenadora da organização na época ${ }^{2}$ e mais dois funcionários presentes em reunião pré-agendada. Foram elaboradas anotações dos pontos principais relatados.

As observações foram feitas por um dos autores deste trabalho, através de caminhadas pelo bairro, visitando o comércio local e a sede da subprefeitura do Itaim Paulista. O objetivo principal era observar as dinâmicas de trabalho desses atores. No período da visita à CAE-IT, os funcionários da instituição não conseguiram encontrar nenhum empreendedor local apoiado por eles, o que comprometeu em parte a profundidade da observação.

\section{Contexto da subprefeitura do Itaim Paulista}

A subprefeitura do Itaim Paulista se localiza no leste do município de São Paulo e é formada por dois distritos: Itaim Paulista e Vila Curuçá, que somam uma área de $21,72 \mathrm{~km}^{2}$, sendo habitada por quase 380 mil habitantes em 2010, com uma densidade demográfica de aproximadamente 17 mil habitantes por km² (Portal da Prefeitura Municipal de São Paulo, 2012). A região é considerada com um perfil de "bairro dormitório", em que os moradores apenas residem no local e trabalham nas regiões mais centrais do município. O comércio nas vias principais é intenso durante todos os dias da semana. A avenida Marechal Tito é a principal da região, onde ficam as estações de trem da Companhia Paulista de Trens Metropolitanos (CPTM), assim como a sede da subprefeitura.

O contexto que se apresenta é de uma região altamente populosa, que possui um baixo nível de renda para o alto custo de vida da cidade de São Paulo. O perfil educacional da população é de baixa escolaridade. De acordo com o Site Itaim Paulista (2012), ${ }^{3} 46 \%$ da população do distrito de Itaim Paulista possui ensino fundamental e 45\% possui ensino médio. Na Vila Curuçá, por sua vez, 43\% e 51\% da população possuem ensino fundamental e médio, respectivamente. Essa característica representa uma dificuldade para o ingresso no mercado de trabalho, o que é agravado principalmente pela falta de qualificação profissional da população, em sua maioria formada por jovens, conforme analisa Martins (2008). De acordo com a Secretaria Municipal do Trabalho (SMTRAB, 2008), ${ }^{4}$ há uma grande quantidade de pessoas jovens (30,8\% com menos de 15 anos, 29,54\% de 15 a 19 anos) sem ocupação e não há disponibilidade de áreas e atividades de lazer ou cultura, o que favorece um alto índice de criminalidade. Cerca de $15,42 \%$ da população total da região depende de benefícios da

\footnotetext{
${ }^{2}$ Chirlene de Moraes.

${ }^{3}$ Dados constantes no site, mas originários do jornal Folha de S.Paulo de 24 de agosto de 2008 (Caderno DNA Paulistano).

${ }^{4}$ Hoje Secretaria de Desenvolvimento Econômico e do Trabalho de São Paulo.
} 
assistência social (SMTRAB, 2008). Quanto ao perfil da renda dos moradores, a tabela 1, a seguir, fornece maiores detalhes:

$$
\text { Tabela } 1
$$

Composição da renda familiar da subprefeitura do Itaim Paulista em salários mínimos (SM)

\begin{tabular}{|lcc|}
\hline Renda familiar & Itaim Paulista & Vila Curuçá \\
\hline Até 2 SM & $34 \%$ & $31 \%$ \\
2 SM a 3 SM & $22 \%$ & $28 \%$ \\
3 SM a 5 SM & $22 \%$ & $24 \%$ \\
5 SM a 10 SM & $11 \%$ & $10 \%$ \\
Acima de 10 SM & $3 \%$ & $4 \%$ \\
\hline
\end{tabular}

Fonte: Site Itaim Paulista ( 2012).

A renda per capita dos dois distritos é de $\mathrm{R} \$ 221,24$ e $\mathrm{R} \$ 244,73$, respectivamente. Dados da subprefeitura (SMTRAB, 2008) apresentam 8.262 empregos formais declarados na região de Itaim Paulista, e a população economicamente ativa (PEA) era de 236.017 cidadãos à época do censo 2000 do Instituto Brasileiro de Geografia e Estatística (IBGE). Isso significa um emprego para cada 26,57 cidadãos da PEA da região, proporção quase 10 vezes maior de cidadãos por vaga que a média do município (Martins, 2008).

De acordo com a Secretaria Municipal do Trabalho (SMTRAB, 2008), a inserção no mercado de trabalho se apresenta como um desafio em Itaim Paulista e Vila Curuçá, sobretudo devido à falta de qualificação profissional e estudo básico (SMTRAB, 2008). É dentro desse contexto de exclusão social e ausência de estrutura de cultura, lazer e educação que se inserem a Vila Curuçá e o Itaim Paulista. A proposta da CAE-IT se mostra ousada na medida em que busca tratar desse contexto de desafios complexos e estruturais - baixa qualificação e educação, ausência de atividades culturais, alto índice de violência, ausência de atividades produtivas no local, bem como emprego e renda, principalmente para a crescente população jovem.

\subsection{A Câmara de Animação Econômica do Itaim Paulista (CAE-IT)}

A CAE-IT é um projeto de geração de ocupação e renda com enfoque no desenvolvimento econômico local, que ocupa lugar de "carro-chefe" no Plano Regional Estratégico da Subprefeitura de Itaim Paulista, município de São Paulo. Foi concebido em 2005, a partir do interesse do então subprefeito Diógenes Sandim. A proposição da CAE-IT é gerar renda e trabalho a partir do empreendedorismo popular, vocação econômica regional e Arranjos Produtivos Locais (Martins, 2008). 
O primeiro passo da concepção da CAE-IT foi o diagnóstico da vocação local. Embora a compreensão das necessidades dos cidadãos já fosse identificada no Plano Diretor Estratégico do município, a subprefeitura do Itaim Paulista aprofundou a análise socioeconômica do território focando nas diferenças intrarregionais. Foram consultados dados secundários como censo do IBGE, Relatório Anual de Informações Sociais (Rais), Índice Paulista de Vulnerabilidade Social, pesquisa Origem Destino do Metrô e dados da Fundação Seade (Martins, 2008). As diversas informações coletadas foram cruzadas, permitindo maior entendimento analítico da realidade local.

Outro fator importante para ganhar profundidade no diagnóstico da realidade local foi a consulta feita a Agentes Comunitárias de Saúde, pela capilaridade e extensão pelo território que representavam. Foram realizados, pela SMTRAB, focus groups ${ }^{5}$ com cerca de 50 agentes, visando compreender como as pessoas se ocupavam e sobreviviam. "A resposta veio imediata e quase em uníssono, 'são costureiras, salgadeiras, boleiras, pedreiros etc."' (SMTRAB, 2006:163). A informalidade do território, que já era comprovada pelos dados secundários, passava a ganhar nome, à medida que as listas recebidas destacavam as "oficinas mecânicas, borracharias, serralherias, marcenarias, bombonieres e boutiques de garagem" (SMTRAB, 2006:163).

Por fim, os dados obtidos foram cruzados com oficinas realizadas junto à comunidade para debater o desenvolvimento econômico local. Foram realizadas 88 oficinas, que culminaram com uma plenária de participação civil, que aplicou a técnica do sociodrama ${ }^{6}$ como forma de proporcionar maior entendimento mútuo e diálogo e a ratificar o diagnóstico que vinha sendo feito. A plenária confirmou a escolha do público-alvo da CAE-IT, empreendedores denominados latentes e emergentes, cujo rendimento mensal é de zero a três salários mínimos. Entendeu-se que essa parcela, correspondente a 43,05\% da população local, teria maiores possibilidades de transformação e intervenção. Foram excluídos, portanto, aqueles que estão na base da pirâmide, em situação de alta vulnerabilidade social. Assim como os que recebem mais de três salários mínimos não necessitariam de uma política voltada para "questões assistencialistas" (SMTRAB, 2006).

Além do público-alvo do programa, o diagnóstico realizado também definiu as atividades econômicas prioritárias, que seriam atendidas na forma de Câmaras Temáticas (CTs). Definiram-se cinco CTs: moda e artesanato; reciclagem; alimentação; cultura e informação e pequenos negócios. As CTs são espaços onde os microempreendedores de cada setor se encontram para obter capacitação técnica e suporte no planejamento estratégico, este último facilitado pelos animadores da CAE-IT (Martins, 2008). O detalhamento de cada CT será feito mais

\footnotetext{
${ }^{5}$ Focus groups é uma técnica utilizada usualmente em pesquisas de mercado qualitativas em que se emprega a discussão moderada por um mediador, contando normalmente com oito a 12 participantes.

${ }^{6} \mathrm{O}$ sociodrama consiste em uma técnica inspirada na criação coletiva teatral e é empregada em terapias de grupo. O grupo escolhe uma situação concreta e a reproduz como em uma peça de teatro, guiado por um instrutor, para permitir aprendizado sobre como se dão as interações sociais vividas pelos participantes. Tanto essa técnica como a do focus group foram aplicadas na região pela SMTRAB.
} 
adiante. A partir das demandas surgidas dos planejamentos estratégicos das CTs, construiu-se a metodologia própria da CAE-IT denominada "6 Cs": 1) caça-talentos; 2) conscientização; 3) capacitação; 4) crédito; 5) cooperação e 6) comercialização (Martins, 2008).

\subsection{Formação das Câmaras Temáticas}

Este subitem descreverá brevemente o histórico de cada Câmara Temática e seu estado atual.

\section{Câmara Temática de Moda}

Esta CT fez o "caça-talentos" por duas vias. A primeira foi a identificação dos 237 CNPJs de empresas de confecção na região e a segunda pelo envolvimento das agentes comunitárias de saúde com grupos de bordadeiras. Entre os 237 CNPJs contatados, a maioria alegava não ter empregados com vínculo CLT trabalhando na produção. Porém, foi diagnosticado na região um alto grau de informalidade no setor, que é caracterizado pela prestação de serviços voltados a atender lojas e fábricas do Brás e Bom Retiro, cuja demanda é esporádica (SMTRAB, 2006). Tendo isso em vista, buscou-se aprofundar o diagnóstico sobre o setor de confecção local, cujo potencial já se mostrava latente.

Os primeiros empreendimentos de confecção da CAE-IT surgiram a partir do envolvimento das agentes comunitárias de saúde que ministravam cursos como "fuxico", tricô, bordado, entre outros, nas Unidades Básicas de Saúde (UBSs). Inicialmente, como atividades de terapia ocupacional, as alunas eram incentivadas a colocar seus produtos no mercado, chegando a comercializá-los em lojas da rua 25 de Março, região de intensa atividade comercial em São Paulo. A partir dessa interação, foram criados os empreendimentos Dorcas e a Cooperativa de Bordadeiras da Cidade Kemel (Cooperkemel). No momento de sua formação, o Grupo Dorcas contava com 48 artesãs e a Cooperkemel contava com 240 artesãs, sendo 150 delas especializadas em bordado em pedraria, 50 fuxiqueiras $^{7}$ e 40 costureiras.

À época, observava-se que esses empreendimentos enfrentavam dificuldades na comercialização de seus produtos, em parte pelo distanciamento em relação à moda vigente. Visando suprir esse ponto fraco, a CAE-IT buscou o apoio de estudantes de design e consultores técnicos. Além disso, buscou aproximar estilistas profissionais da região para ampliar a rede de contato dos grupos. Foram selecionadas cerca de 20 líderes comunitárias de ambos os grupos para realizar as capacitações em design e tendências de mercado, para que pudessem em seguida se tornar multiplicadoras desse conhecimento para as outras artesãs.

O grupo Cooperkemel apresentava baixo grau de especialização (assim como de escolaridade), baixa capacidade gerencial e ausência de controle de qualidade da produção. Além

${ }^{7}$ Fuxico é um tipo de artesanato feito com tecido. 
disso, os conflitos de interesse e interpessoais dificultavam o trabalho diário. Embora esse diagnóstico realizado durante os primeiros meses da incubação fosse desfavorável, o comportamento empreendedor de muitas artesãs representava grande potencial e por isso se optou pelo assessoramento do grupo. Já o grupo Dorcas realizava a distribuição dos serviços internos de forma satisfatória e possuía controle de qualidade da produção. Entretanto, enfrentava dificuldades na comercialização dos produtos. A CAE-IT concluiu que deveria concentrar seus esforços na capacitação e comercialização da Câmara. A primeira envolveu a capacitação técnico-gerencial e a segunda resultou na Operação Santo Antônio. Esta consistiu no esforço de aproximar os comerciantes de médio e pequeno porte com a finalidade de capacitar os grupos de acordo com seus padrões de qualidade e estilo.

\section{Câmara Temática de Reciclagem}

Nesse caso, a CT também se formou a partir da interação de uma das representantes dos agentes de saúde com a comunidade. A agente Cilene tinha forte envolvimento com os catadores e Núcleos de Reciclagem, oferecendo apoio junto aos órgãos governamentais. Esses Núcleos eram formados em sua maioria por mulheres que haviam realizado os cursos de capacitação ambiental promovidos pela gestão anterior. Entre os atores ligados à economia da reciclagem da região, os Núcleos de Reciclagem se destacavam por seu perfil de trabalho. As catadoras se comprometiam com a coleta porta a porta e atuavam como agentes ambientais ao promover a sensibilização ambiental e fidelização das casas com sua coleta. Além disso, mantinham uma postura ética de não aceitar descarte de materiais furtados, fator importante que lhes deu maior credibilidade ante o poder público. A formação da CT de reciclagem ocorreu a partir da interação com os núcleos de reciclagem e aos poucos passou a contar com a participação dos pequenos ferros-velhos, cooperados da Central de Triagem da Vila Curuçá, catadores autônomos e dirigentes do Departamento de Limpeza Urbana da Secretaria Municipal de Serviços (Limpurb).

Uma das ações da CT de reciclagem foi a demarcação dos ecopontos de forma inovadora. A concepção inicial dos ecopontos é de servir como espaços de entrega voluntária de resíduos recicláveis e entulhos da construção civil e objetos inservíveis como móveis, eletrodomésticos etc. A subprefeitura do Itaim Paulista teve o mérito de sensibilizar parceiros importantes para acordos intersetoriais. A Limpurb construiu os ecopontos, no espaço cedido pela Companhia de Desenvolvimento Habitacional Urbano (CDHU) e reconheceu a Central de Triagem e Comercialização do Distrito do Itaim Paulista. Além disso, a subprefeitura, junto aos parceiros, conseguiu construir o arranjo legal que permitiu a concessão de uso dos ecopontos para as cooperativas. Esse arranjo representou uma inovação do ponto de vista administrativo e funcionou como ponto de alavancagem para as cooperativas iniciarem suas atividades formalmente.

Entre as atividades da CT de reciclagem incluem-se a capacitação dos cooperados, a assessoria para captação de recursos e a assessoria técnica de mapeamento do potencial de 
reciclagem e localização dos ecopontos. Essa foi considerada uma das mais bem-sucedidas CTs, tendo a cooperativa Fênix Ágape atingido o nível de emancipação da câmara. Atualmente a cooperativa possui parceria com a prefeitura para a triagem dos resíduos coletados nos ecopontos.

\section{Câmara Temática de Alimentação}

Esta CT foi formada a partir da percepção dos Agentes Comunitários de Saúde e pela verificação de um grande número de pessoas capacitadas. Havia registros de pessoas formadas em cursos do Centro Municipal de Capacitação e Treinamento (parceria CMCT/Senai), pelas Padarias Comunitárias do Governo do Estado e pelas diversas associações eclesiásticas do bairro (SMTRAB, 2006). Essas pessoas foram incentivadas a comercializar sua produção por meio de empreendimentos populares, tendo acesso a capacitações em empreendedorismo do Sebrae e a conhecimentos de aspectos técnicos da manipulação de alimentos. A CT articulou parceiros para a realização das oficinas de capacitação, bem como para a comercialização dos alimentos produzidos. O grupo Sonda Supermercados foi um dos parceiros que ofereceu um espaço de comercialização em suas instalações. Atualmente, poucos empreendimentos sobreviveram à mortalidade empresarial. Muitos deles vendem seus produtos na feira de artesanato semanal do bairro.

Em uma das entrevistas realizadas, foi apontada a dificuldade de se adequar os "tempos" dos parceiros ao tempo da incubação. A necessidade de capacitações específicas, sob demanda, dos empreendimentos, muitas vezes era incompatível com os módulos "prontos" dos parceiros, cujos pré-requisitos (horas de cursos básicos anteriores) não lhes permitia realizar as capacitações pontuais. Atualmente, os grupos formados estão dispersos e poucas pessoas os mantêm em funcionamento. Formaram-se pequenos grupos que produzem para vender na feira semanal do bairro e outros atendem à produção da grande indústria.

\section{Câmara Temática de Cultura e Informação}

A partir dos movimentos de jovens ligados a temas como música, eventos, literatura, esportes e outros, formou-se a CT de Cultura e Informação. Esses jovens possuíam habilidades de articulação, sobretudo demonstradas na busca de patrocínios pelo poder público para seus eventos e oficinas. Pensou-se que poderiam aportar essas habilidades como um apoio transversal às outras CTs. Além disso, verificou-se que os jovens poderiam desenvolver os bancos de dados e coleta das informações que seriam utilizadas pela CAE-IT. Formou-se, então, a Coopermira Peripheria Digital, responsável pela construção da Base Comum de Conhecimento Ci- 
dadão (BCCC). Entre as atribuições da BCCC, visava-se contribuir para a formação de jovens como gestores sociais no uso das informações sobre o contexto local, buscando democratizar o acesso da população à informação. A cooperativa também organiza eventos multimídia de Economia Solidária, elabora sites com o portfólio dos produtos locais, assim como a criação de artes gráficas para a cadeia de moda e design. Essa CT também agrega o Arranjo Produtivo de Artesanato. Atualmente, a grande maioria dos empreendimentos de base artesanal produz em pequena escala e comercializa na feira semanal de artesanato da praça Silva Telles, localizada no bairro.

\section{Câmara Temática de Pequenos Negócios}

Esta CT tem fomentado especialmente dois ramos de trabalho: a construção civil e o apoio aos ambulantes do Itaim Paulista. Identificou-se que havia diversos prestadores de serviço em construção civil, assim como a possibilidade de parcerias importantes para iniciar um APL do setor. Foi formada a Cooperativa de Mão de Obra de Construção Civil (Coomaco), incubada pela Associação Nacional dos Lojistas de Materiais de Construção Civil (Anamaco). O Serviço Nacional da Indústria (Senai), por sua vez, contribuiu com a capacitação dos cooperados. Outra via importante da CT Pequenos Negócios é o apoio à Associação de Vendedores Ambulantes do Itaim Paulista, a fim de obter segurança jurídica para seu funcionamento, por intermédio do novo amparo possibilitado pela categoria Microempreendedor Individual (MEI).

\subsection{Autoavaliação da CAE-IT}

De acordo com relatório de 2008 da CAE-IT (Martins, 2008), durante o primeiro ciclo da Câmara (2005-06), a autoavaliação era centrada no incremento da renda dos beneficiários. Entretanto, constatou-se que esse indicador não avaliava adequadamente os esforços das CTs, pois nem sempre o aumento na renda representava avanços no trabalho de acompanhamento. Para o ciclo seguinte (2007-08), foram incorporadas as seguintes premissas para o planejamento:

a) as limitações dos beneficiários eram maiores do que haviam sido estimadas inicialmente; b) até aquele momento, a CAE-IT ainda não dispunha de ferramentas suficientes para a incubação de microempreendimentos, nem mesmo contando com os parceiros e, c) a fim de assegurar a sua sustentabilidade, a CAE-IT deveria capacitar seu próprio quadro funcional e diminuir a dependência dos consultores externos, que eram parceiros ou voluntários eventuais (Martins, 2008:10).

A seguir, na tabela 2, apresenta-se o número de beneficiários em cada um dos "6 Cs" da metodologia: 
Tabela 2

Resultados quantitativos até nov. 2008 (em número de beneficiários do projeto)

\begin{tabular}{|c|c|c|c|c|c|c|}
\hline & Moda & Reciclagem & Alimentação & $\begin{array}{l}\text { Cultura e Infor- } \\
\text { mação }\end{array}$ & $\begin{array}{l}\text { Pequenos } \\
\text { Negócios }\end{array}$ & Total \\
\hline Caça-talentos & 382 & 210 & 151 & 68 & 575 & 1386 \\
\hline Conscientização & 382 & 210 & 151 & 68 & 575 & 1386 \\
\hline Capacitação & 382 & 40 & 57 & 68 & 95 & 642 \\
\hline Crédito & 3 & 0 & 2 & 0 & 4 & 9 \\
\hline Cooperação & 140 & 210 & 44 & 40 & 80 & 514 \\
\hline Comercialização & 140 & 20 & 44 & 32 & 80 & 316 \\
\hline $\begin{array}{l}\text { № de pessoas que } \\
\text { tiveram incremento na } \\
\text { renda }\end{array}$ & 143 & 210 & 45 & 32 & 106 & 536 \\
\hline
\end{tabular}

Fonte: Adaptado de Portal da Prefeitura Municipal de São Paulo (2010).

A CAE-IT não tem registros públicos de resultados de 2008 até 2011. Em 2009, a gestora Mirna Oliveira faleceu e desde então a Câmara não tem compilado os registros de beneficiários e outros indicadores de desempenho do projeto.

\subsection{Articulação de parceiros}

A CAE-IT conseguiu articular diversas parcerias ao projeto, que incluem desde universidades a outras instâncias de governo, centros de capacitação, comerciantes, empresas, órgãos multilaterais e consultores voluntários e remunerados. Essa capacidade de articular parcerias em diversas instâncias e frentes é um dos pontos fortes da CAE-IT. O projeto representa uma possibilidade de mudanças significativas no contexto da periferia de São Paulo. Para os atores mais próximos envolvidos, como os consultores, representava uma espécie de laboratório para promover transformação social. Eles participaram da política mesmo quando ainda não havia recursos para remunerá-los, como o caso da consultora em desenvolvimento local Luzia Soares. Quando terminaram os recursos, alguns consultores permaneceram ligados ao projeto voluntariamente.

O relatório de 2008 da CAE-IT (Martins, 2008) faz a compilação dos aportes realizados pelos principais parceiros do projeto, sem contabilizar outros parceiros que ajudaram em questões mais pontuais. A tabela 3 divide os aportes em financeiros, consistindo no próprio financiamento da CAE-IT, e econômicos, que assumem a forma de horas técnicas cedidas, capacitações, construção civil etc. O aporte financeiro realizado pela CAE-IT diz respeito somente à folha de pagamento dos funcionários. Como pode ser observado, apenas o projeto BRA/05/033 aportou recursos financeiros à CAE-IT, a partir de dinheiro do Programa das 
Nações Unidas para o Desenvolvimento (PNUD), tendo a Secretaria Municipal do Trabalho ${ }^{8}$ como agência executora e a Fundação Escola de Sociologia e Política de São Paulo (Fesp-SP) como agência implementadora.

Tabela 3

\section{Composição orçamentária 2005-08}

\begin{tabular}{|c|c|c|c|c|}
\hline \multirow[b]{2}{*}{ Parceiros de compromisso } & \multicolumn{2}{|c|}{ Aportes financeiros } & \multicolumn{2}{|c|}{ Aportes econômicos } \\
\hline & 2005-06 & 2007-08 & 2005-06 & 2007-08 \\
\hline $\begin{array}{l}\text { Caeit-Folha de pagamentos e despesas } \\
\text { administrativas }\end{array}$ & $\mathrm{R} \$ 557.108,40$ & $R \$ 545.200,00$ & & \\
\hline $\begin{array}{l}\text { CMCT - Senai-Cursos influenciados pela } \\
\text { Caeit }\end{array}$ & & & $\mathrm{R} \$ 215.000,00$ & \\
\hline Voluntários - horas técnicas & & & $\mathrm{R} \$ 300.000,00$ & $R \$ 120.000,00$ \\
\hline $\begin{array}{l}\text { Projeto BRA/05/033- } \\
\text { PNUD/SMTRAB/Fesp-SP }\end{array}$ & $\mathrm{R} \$ 300.000,00$ & & & \\
\hline $\begin{array}{l}\text { SP Confia-Créditos concedidos na } \\
\text { jurisdição }\end{array}$ & & & $R \$ 3.600 .000,00$ & $R \$ 4.000 .000,00$ \\
\hline $\begin{array}{l}\text { Banco do Povo Paulista - para créditos } \\
\text { a serem concedidos }\end{array}$ & & & $R \$ 1.000 .000,00$ & \\
\hline $\begin{array}{l}\text { Sebrae - Serviços especialmente } \\
\text { contratados para atender o Itaim Paulista }\end{array}$ & & & $R \$ 59.636,72$ & $\mathrm{R} \$ 197.050,96$ \\
\hline Instituto Lidas - oficinas & & & $\mathrm{R} \$ 42.000,00$ & $R \$ 14.000,00$ \\
\hline Ibim - oficinas & & & $R \$ 22.000,00$ & \\
\hline Limpurb - construção de ecopontos & & & $\mathrm{R} \$ 250.000,00$ & \\
\hline $\begin{array}{l}\mathrm{CDHU} \text { - instalações da central de } \\
\text { triagem e comercialização }\end{array}$ & & & $\mathrm{R} \$ 700.000,00$ & \\
\hline \multirow[t]{3}{*}{ Total } & $\mathrm{R} \$ 857.108,40$ & $R \$ 545.200,00$ & $R \$ 6.188 .636,72$ & $R \$ 4.331 .050,96$ \\
\hline & \multicolumn{2}{|c|}{$R \$ 1.402 .308,40$} & \multicolumn{2}{|c|}{$R \$ 10.519 .687,68$} \\
\hline & \multicolumn{4}{|c|}{$R \$ 11.921 .996,08$} \\
\hline
\end{tabular}

Fonte: Martins (2008).

Além do PNUD e a própria subprefeitura do Itaim Paulista, os outros parceiros aportaram exclusivamente recursos econômicos sob a forma de capacitações, consultoria, construção civil e outros serviços. A quantidade de parcerias e a dimensão dos recursos por eles aportados demonstram a capacidade de articulação e empreendedorismo dos agentes da CAE-IT. A figu-

\footnotetext{
${ }^{8}$ Como já foi mencionado anteriormente, hoje Secretaria de Desenvolvimento Econômico e do Trabalho de São Paulo.
} 
ra do subprefeito Diógenes, que inclusive ganhou o prêmio Sebrae de prefeito empreendedor, foi significativa para esse resultado. E, atualmente, os próprios servidores se veem como captadores de recursos e articuladores de parceiros.

O potencial de nucleação (Silveira, Bocayuva e Zapata, 2001) do projeto e de seus agentes é uma característica da CAE-IT, podendo ser considerado um dos principais fatores que permitiram o desenvolvimento do projeto. As competências de articulação de parceiros, proatividade, flexibilidade, abertura para a inovação, olhar intersetorial e sistêmico foram fundamentais para a concepção da CAE-IT. A presença dessas competências será requerida ao se pensar na replicação da metodologia.

\subsection{Análise econômico-financeira × número de beneficiários}

Ao comparar a tabela 2 (resultados quantitativos até nov. 2008) com a tabela 3 (composição orçamentária 2005-08), podem ser inferidas informações sobre a quantidade de recursos investidos em relação ao número de beneficiários do projeto.

Uma reflexão pode ser feita a partir da seguinte análise: se dividirmos o total de aportes financeiros e econômicos entre 2005 e 2008 (R\$ 11.921.996,08) pelo total de beneficiários que tiveram incremento de renda no mesmo período, teremos o valor de $\mathrm{R} \$ 22.242,53$ por pessoa. Ou seja, caso o projeto tivesse doado essa quantia para 536 pessoas, cada uma teria recebido $\mathrm{R} \$ 463,38$ por mês ao longo de quatro anos. Cabe salientar que uma análise financeira como essa exclui quaisquer indicadores de melhoria da qualidade de vida, aumento da autoestima das pessoas, assim como desconsidera o número de pessoas que realizaram as capacitações e não tiveram incremento de renda. Não é possível afirmar que, do ponto de vista estritamente financeiro, teria sido melhor realizar a doação de $\mathrm{R} \$ 463,38$ para as 536 pessoas que tiveram algum tipo de incremento de renda, pela ausência de outros dados, como o valor do aumento da renda dessas pessoas.

Outro aspecto que chama a atenção é a quantidade de recursos investidos na instalação das agências de microcrédito (total de $\mathrm{R} \$$ 8.600.000,00) para o número de pessoas que efetivamente tomaram crédito: nove. A justificativa dada pela CAE-IT para o baixo número de tomadores de crédito é que a maioria das pessoas não é elegível ao microcrédito por estar com nome cadastrado em órgãos de proteção ao crédito. Os beneficiários do microcrédito têm sido as pessoas que não têm passado pela CAE-IT.

\section{Discussão dos resultados}

A Câmara de Animação Econômica do Itaim Paulista é um projeto que buscou inovar na forma e na concepção de uma política pública de desenvolvimento local. O projeto se destaca por sua constante preocupação de compreender a realidade local e se adaptar a ela. Conseguiu ter um olhar abrangente, mas sem perder de vista os detalhes. Isso fica claro na 
medida em que articulou a análise dos dados georreferenciados com a percepção das agentes comunitárias de saúde.

O embasamento teórico e a inspiração em boas práticas definiram o foco da CAE-IT em formar arranjos produtivos locais como estratégia do desenvolvimento local, aproveitando oportunidades de negócios existentes na região, como sugerido por Cassiolato e Lastres (2003). Também fruto da percepção das agentes de saúde e da revisão teórica, foram definidos o público-alvo — empreendedores latentes — e a metodologia dos "6 Cs" como abordagem do projeto.

A observação da realidade atual das câmaras aponta para o sucesso da CT reciclagem, cuja principal cooperativa foi desincubada, o mesmo tendo ocorrido com a CT Cultura e Informação no caso da Coopermira Digital. No caso das outras CTs, a maioria dos empreendimentos terminou ou se estagnou num patamar de baixo incremento de renda. Há, entretanto, casos de beneficiários da CAE-IT que têm perfil extremamente empreendedor e bastava algum apoio de gestão ou crédito para expandirem seus negócios.

A CAE-IT recebe diariamente dezenas de cidadãos que buscam algum tipo de orientação para melhorar seu próprio negócio. Para essas pessoas tem oferecido cursos do Sebrae e outros parceiros de acordo com a necessidade. Desse ponto de vista, tem tido sucesso ao apoiar pontualmente essa demanda. Já no caso da formação de empreendimentos, que requer o acompanhamento mais próximo, tem enfrentado dificuldades inerentes à sua estrutura: falta de pessoal e dependência dos parceiros. Uma sugestão para a CAE-IT seria a oferta do serviço de incubação de empreendimentos selecionados. Esse assessoramento poderia formar os grupos com maior dedicação e atendendo aspectos mais específicos que requerem atenção constante, como a formação grupal dos membros dos empreendimentos.

Se retomarmos os aspectos do planejamento do desenvolvimento local proposto por Blakely e Bradshaw (2002), pode-se afirmar que a CAE-IT atende a todas as fases do planejamento. Entretanto, o projeto não se desenvolveu a partir do planejamento antecipado e totalmente estruturado, mas sim como encaminhamentos adaptados ao longo do tempo, conforme apontam Camarotti e Spink (2003). Essa capacidade de adaptação ao contexto local, das demandas locais e das articulações com os parceiros representa um componente estrutural para a questão de planejar o desenvolvimento local.

Levando em conta o risco de "reproduzir uma tecnologia em série que privilegia tudo e nada ao mesmo tempo" (Camarotti e Spink, 2003:194), a possibilidade de replicação da metodologia deveria considerar o modelo proposto por Silveira, Bocayuva e Zapata (2001), em que muito mais do que buscar replicar as práticas, deveria, sim, replicar a intenção da construção coletiva entre os atores, voltada ao aprendizado contínuo.

A formulação da CAE-IT buscou teorias e melhores práticas de forma a embasar sua ação, que foi legitimada pela busca do entendimento do território. O uso do sociodrama e a articulação das agentes comunitárias representam a postura de buscar entender o públicoalvo e envolvê-lo efetivamente no projeto. Essa postura perante as pessoas, denominadas público-alvo, é que representa a "boa prática". 
Outro fator importante do projeto é que ele requer uma capacidade própria do comportamento empreendedor, que é a articulação de parceiros, considerada vital para o sucesso deste tipo de política por alguns autores (Spink, 2001; Vasconcellos e Vasconcellos, 2009; Martins e Caldas, 2009). Portanto, deve-se levar em consideração que a possibilidade de replicação da metodologia em outros locais precisa prever gestores com essa capacidade de articulação. E essa capacidade, por sua vez, conforme atestado pela estrutura organizacional da CAE-IT, se dá tanto pelo perfil e competência do servidor público, como pela estrutura organizacional que lhe motiva, incentiva e concede espaço para "costurar" parcerias. Cabe lembrar que nem toda subprefeitura ou subprefeito está preparado para construir uma estrutura na organização que permita esse tipo de ação "empreendedora".

Conforme formula Nogueira (2006), a intencionalidade é um fator importante para diminuir o risco de descontinuidade administrativa. A tentativa de compreender a realidade local e customizar um projeto de desenvolvimento local demanda esforços e recursos. Embora seja importante, não basta que as instâncias superiores apoiem o projeto, mas os atores locais precisam estar motivados para que ele ocorra e obtenha sucesso.

\section{Considerações finais}

Promover o desenvolvimento econômico local endógeno, voltado às pessoas de baixa renda e baixa instrução, representa um grande desafio. Significa enfrentar questões estruturais de um contexto e conseguir "dançar” com esse mesmo contexto. É dançar sob o ritmo da música, ao mesmo tempo que se busca conduzir o trajeto da dança para um lugar almejado.

A CAE-IT é um projeto que inovou em diversos aspectos, começando pela atuação dentro da subprefeitura, que excedeu as obrigações delegadas à unidade da prefeitura. Sob o alicerce dado pela motivação e o desejo de transformação social, um grupo de indivíduos se tornou um grupo de agentes articulados que aportou seus recursos, conhecimentos e trabalho a serviço do desenvolvimento daquele território. Um dos principais aspectos responsáveis pelo desenvolvimento da CAE-IT é o rol de parceiros que agregou ao projeto desde seu início, em 2005. Inicialmente, a postura empreendedora do subprefeito, seguido por outros servidores e consultores da CAE-IT, foi decisiva para o desenvolvimento do projeto. Os estudos sobre desenvolvimento regional ou local apontam para diversos caminhos e possibilidades, mas que não devem ser tomados como "receitas prontas". Fica claro na experiência do Itaim Paulista que a predominância da motivação e o esforço dos agentes em transformar o local é que construíram a própria receita do seu desenvolvimento.

Ao mesmo tempo que o ponto forte do projeto é o conjunto de recursos aportados pelos parceiros, esse também é um ponto de vulnerabilidade para a Câmara, pois, na medida em que os parceiros terminam ou rompem sua parceria, a CAE corre o risco da descontinuidade das ações. Além disso, precisa constantemente se adequar às metodologias e aos cronogramas dos parceiros, o que não necessariamente condiz com a demanda requerida pelo empreendimento atendido. Por fim, a CAE parte da premissa da formação de arranjos produtivos locais 
(APLs) como estratégia de ganhos de escala e competitividade para o desenvolvimento econômico local. Essa premissa merece análise mais aprofundada, sendo uma sugestão de estudos posteriores. Pois nenhuma das câmaras, com exceção da CT reciclagem, se articulou em um arranjo produtivo. E mesmo a CT reciclagem ainda se organiza em um arranjo incipiente.

\section{Referências}

ABRAMOVAY, Ricardo. O capital social dos territórios: repensando o desenvolvimento rural. Economia Aplicada, v. 4, n. 2, p. 379-397, 2000.

AMARAL FILHO, Jair do. A endogeneização no desenvolvimento econômico regional e local. Planejamento e Políticas Públicas, n. 23, p. 261-286, 2001.

BLAKELY, Edward J.; BRADSHAW, Ted K. Planning local economic development. Thousand Oaks, Califórnia: Sage, 2002.

BUARQUE, Sérgio C. Metodologia de planejamento do desenvolvimento local e municipal sustentável. Material para orientação técnica e treinamento de multiplicadores e técnicos em planejamento local e municipal. Brasília: IICA, 1999.

CAMAROTTI, Ilka. Construção de indicadores de desenvolvimento local. In: CONGRESSO INTERNACIONAL DEL CLAD SOBRE LA REFORMA DEL ESTADO Y DE LA ADMINISTRACIÓN PÚBLICA, IX, Madri, 2004.

CAMAROTTI, Ilka; SPINK, Peter K. (Org.). Estratégias locais para redução da pobreza: construindo a cidadania. 2. ed. São Paulo: Eaesp, 2003.

CASSIOLATO, José E.; LASTRES, Helena M. O foco em arranjos produtivos e inovativos locais de micro e pequenas empresas. In: LASTRES, Helena M. et al. (Org.). Pequena empresa: cooperação e desenvolvimento local. Rio de Janeiro: Relume Dumará, 2003. cap. 1, p. 21-34.

CASSIOLATO, José E.; SZAPIRO, Marina. Uma caracterização de arranjos produtivos locais de micro e pequenas empresas. In: LASTRES, Helena M. et al. (Org.). Pequena empresa: cooperação e desenvolvimento local. Rio de Janeiro: Relume Dumará, 2003. cap. 2, p. 35-50.

CLEMENTE, Ademir; HIGACHI, Hermes Y. Economia e desenvolvimento regional. São Paulo: Atlas, 2000.

DE PAULA, Juarez. Desenvolvimento e gestão compartilhada. In: SILVEIRA, Caio M.; REIS, Liliane da C. (Org.). Desenvolvimento local: dinâmicas e estratégias. Rio de Janeiro: Rede Dlis/Rits, 2001.

ITAIM PAULISTA. Itaim Paulista em números. Disponível em: <www.itaimpaulista.com.br/portal/ index.php? secao=datafolha $>$. Acesso em: 26 abr. 2012.

LASTRES, Helena M. et al. (Org.). Pequena empresa: cooperação e desenvolvimento local. Rio de Janeiro: Relume Dumará, 2003.

MARSHALL, Alfred. Princípios de economia. São Paulo: Nova Cultural, 1996. 
MARTINELLI, Dante P.; JOYAL, André. Desenvolvimento local e o papel das pequenas e médias empresas. Barueri: Manole, 2004.

MARTINS, Diógenes S. Prêmio São Paulo Cidade 2008. São Paulo: Secretaria de Coordenação das Subprefeituras, 2008.

MARTINS, Rafael D.; CALDAS, Eduardo de L. Visões do desenvolvimento local: uma análise comparada de experiências brasileiras. Interações, v. 10, n. 2, p. 207-218, 2009.

MARTINS, Rafael D.; VAZ, José C.; CALDAS, Eduardo de L. A gestão do desenvolvimento local no Brasil: (des)articulação de atores, instrumentos e território. Revista de Administração Pública, Rio de Janeiro, v. 44, n. 3, p. 559-90, 2010.

MEYER-STAMER, Jörg. Por que o desenvolvimento econômico local é tão difícil, e o que podemos fazer para torná-lo mais eficaz? São Paulo: Fundação Friedrich Ebert Stiftung, 2004.

NOGUEIRA, Fernando do A. Continuidade e descontinuidade administrativa em governos locais: fatores que sustentam a ação pública ao longo dos anos. Dissertação (mestrado em administração pública e governo) - Escola de Administração de Empresas de São Paulo, Fundação Getulio Vargas, São Paulo, 2006.

PORTAL DA PREFEITURA MUNICIPAL DE SÃO PAULO. Dados demográficos dos distritos pertencentes às subprefeituras. Disponível em: <www.prefeitura.sp.gov.br/cidade/secretarias/subprefeituras/ subprefeituras/dados_demograficos/index.php?p=12758>. Acesso em: 26 abr. 2012.

PORTAL DA PREFEITURA MUNICIPAL DE SÃO PAULO. Apresentação Câmara de Animação Econômica do Itaim Paulista. Disponível em: <www.prefeitura.sp.gov.br/cidade/secretarias/upload/2_camara_de_animacao_economica_itaim_paulista_1259244484.pdf >. Acesso em: 10 jan. 2010.

PORTER, Michael. The competitive advantage of Nations. Nova York: Free Press, MacMillan, 1990.

SAUSEN, Jorge O.; PATIAS, Ivete A.: ALLEBRANDT, Sérgio L. Desenvolvimento local e estratégia de pequenos empreendimentos agroindustriais — a lógica da cooperação e do associativismo: o Pacto Fonte Nova. Cadernos Ebape, v. 9, n. 3, p. 868-894, 2011.

SILVA, José F.M. da; TONDO, Isabel de S.P.; LIMA, Jandir F. Desenvolvimento local em Guaíra-PR: impasses e alternativas. Interações, v. 8, n. 2, p. 165-174, 2007.

SILVEIRA, Caio; BOCAYUVA, Cunca; ZAPATA, Tânia. Ações integradas e desenvolvimento local: tendências, oportunidades e caminhos. In: SPINK, Peter K.; BAVA, Sílvio C.; PAULICS, Veronika (Org.). Novos contornos da gestão local: conceitos em construção. São Paulo: Pólis/Eaesp-FGV, 2001.

SMTRAB. Secretaria Municipal do Trabalho de São Paulo. Desenho e implantação de projeto piloto de arranjos produtivos locais e suas oportunidades de geração de ocupação e renda. São Paulo: SMTrab/PMSP, 2006.

SMTRAB. Secretaria Municipal do Trabalho de São Paulo. Fomento ocupacional e desenvolvimento local: a SMTrab e a Câmara de Animação Econômica do Itaim Paulista. São Paulo: SMTrab/PMSP, 2008. 
SPERANZA, Juliana S. Limites e possibilidades do desenvolvimento Local. Sinais Sociais, v. 1, n. 2, p. 142-187, 2006.

SPINK, Peter K. Parcerias e alianças com organizações não estatais. In: SPINK, Peter K.; BAVA, Sílvio C.; PAULICS, Veronika (Org.). Novos contornos da gestão local: conceitos em construção. São Paulo: Pólis/Eaesp-FGV, 2001.

VASCONCELLOS, Mário; VASCONCELLOS, Ana M. Partnership, empowerment and local development. Interações, v. 10, n. 2, p. 133-148, 2009.

YIN, Robert K. Estudo de caso: planejamento e métodos. 2. ed. São Paulo: Bookman, 2001.

Carmen Augusta Varela é professora adjunta I do programa de mestrado e doutorado em administração do Centro Universitário da FEI-SP e professora extracarreira da Escola de Administração de Empresas de São Paulo, da Fundação Getulio Vargas (FGV-Eaesp). E-mail: cvarela@fei.edu.br.

Cesar Yojiro Matsumoto 9 é administrador público pela FGV-Eaesp, consultor associado do Instituto Tellus e professor da Escola de Diálogo de São Paulo. E-mail: cesar.matsumoto@tellus.org.br.

\footnotetext{
${ }^{9} \mathrm{O}$ autor participou do Programa Pibic/CNPq pela FGV-Eaesp.
} 